\title{
Development of a numerical simulation model for suction rate using CADMAS-SURF
}

\author{
Kornvisith Silarom ${ }^{1, *}$, Yoshimichi Yamamoto ${ }^{2}$, Syota Yoshizawa $^{3}$ and Nunthawath Charusrojthanadech ${ }^{4}$ \\ ${ }^{1}$ Graduate School of Science and Technology, Tokai University, Hiratsuka, Kanagawa, Japan \\ ${ }^{2}$ Department of Civil Engineering, Tokai University, Hiratsuka, Kanagawa, Japan \\ ${ }^{3}$ Graduate School of Engineering, Tokai University, Hiratsuka, Kanagawa, Japan \\ ${ }^{4}$ Department of Civil Engineering, Faculty of Engineering, King Mongkut's Institute of Technology Ladkrabang, Bangkok, Thailand
}

\begin{abstract}
There are many cases where a coastal dike or a seawall constructed on a very shallow area was broken by a wave of a smaller height than the designed height. In many of these cases, the reason of the destruction was the suction phenomena. This phenomenon happens when waves reaches the front of the dike or the seawall, the wave pressure scours the front soil of the structure until it reaches the lowest edge of the structure followed by sucking of backfilling material of the structure. In this research, the authors proposed the numerical model which can calculate the suction rate with elapsed time by applying the pore water pressure and the flow velocity inside a dike or a seawall using "CADMAS-SURF". The authors proposed three coefficients for improving the calculated pressure from CADMAS-SURF. The reliability of the model was confirmed by reproducing the suction phenomena in Hirono Coast of Japan.
\end{abstract}

\section{Introduction}

There are many cases where a coastal dike or a seawall in a very shallow area was broken by repeating action of smaller waves than the designed wave. The main reasons of destructions are scouring in front of the structure, and suction from the inside of the structure. The suction phenomena occurred when the wave pressure scoured all the front soil layer of the structure, and then, the return flow sucks the backfilling materials out of the structure. If the structure loses its stability due to backfilling material loss, it will collapse. So, to design coastal facilities in the shallow area, it is important to consider the scouring and the suction phenomena.

Yamamoto et al. [1] found that the suction rate is proportional to the difference between shear force and shear resistance at the bottom of the structure (refer to Fig.1). Moreover, they proposed the empirical equation which can predict the failure of the structure.

Ioroi et al. [2,3] proposed an empirical equation for calculating the suction rate using pore water pressure and velocity at the lowest edge of the structure. This equation can calculate the suction rate with sufficient accuracy. However, this equation is limited to the shape of the structure. They also evaluated the accuracy of their equation by using calculated pore water pressure and velocity from the numerical simulation model "CADMAS-SURF". However, the calculated results are not satisfying because this numerical model cannot consider the effect of porous media. To handle the above defect, Yoshizawa et al. [4] proposed an empirical equation for getting a modification coefficient. This coefficient can take the effect of median grain size into account.

In this research, the authors proposed a new suction rate formula which can calculate suction rates with elapsed time by using calculated pressure and velocity from CADMAS-SURF. Moreover, CADMAS-SURF cannot consider the effect of porous media consisting of fine grain such as sand or gravel, the authors proposed some empirical equations for calculating modification coefficient to improve the calculated pressure and velocity from CADMAS-SURF.

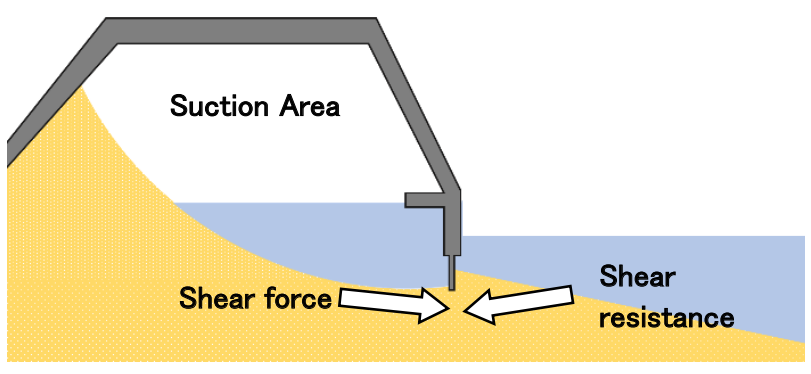

Fig.1 Illustration of suction in a coastal dike.

\section{Related Literature}

\subsection{Original Suction Rate Formula}

Ioroi et al. [2, 3] purposed a formula (Eq. (1)) for calculating the suction rate of the coastal dike or the seawall which the front side and the crown side are covered by concrete or asphalt. They proposed the

\footnotetext{
* Corresponding author: 7ltad005@mail.u-tokai.ac.jp
} 
empirical equation, Eq. (3), for calculating the proportional coefficient $(\beta)$ between the suction rate and the difference between shear force and shear resistance by using hydraulic experiments. This coefficient could convert the difference between the shear force and the shear resistance at the lowest edge of the structure to the suction rate with sufficient accuracy.

$$
\begin{gathered}
\frac{q}{w_{s} D_{50}}=\beta\left(\theta-\theta_{c}\right) \frac{1}{2}\left(1+\cos \left(\frac{\alpha T}{t}\right)\right), \\
-9.0 \times 10^{-5}\left(\frac{D_{50}}{0.2 m m}\right)+0.0031,\left[1 \leq \frac{D_{50}}{0.2 m m} \leq 25\right] \\
-3.39 \times 10^{-5}\left(\frac{D_{50}}{0.2 m m}\right)+0.0017,\left[25 \leq \frac{D_{50}}{0.2 m m} \leq 50\right] \\
\beta=0.028 e^{-0.35\left(\frac{D 50}{0.2 m m}\right)} \\
\theta_{c}=\tau_{r} /\left(\rho_{s}-\rho_{w}\right) g D_{50}, \\
\theta=\tau_{f} /\left(\rho_{s}-\rho_{w}\right) g D_{50}, \\
\tau_{r}=\left(\rho_{s} g d_{t}-\rho_{w} g d_{t}-P_{o b \max }\right) \tan \phi, \\
\tau_{f}=\frac{1}{2} f \rho_{w} V_{\max }^{2}, \\
V_{\text {max }}=\sqrt{2\left(\frac{P_{o b \max }}{\rho_{w}}\right)\left(\frac{h}{H}+1.0\right)^{-1.11}}
\end{gathered}
$$

where, $q$ is the suction rate per unit width at the lowest edge of the structure, $w_{s}$ is the settling velocity of Rubey's, $D_{50}$ is the median grain size, $\theta_{c}$ is the dimensionless critical suction force, $\theta$ is the dimensionless suction force, $T$ is the wave period, $t$ is the time, $\alpha$ is the reduction coefficient, $\beta$ is the proportional coefficient, $\tau_{r}$ is the shear resistance, $\tau_{f}$ is the suction force (shear force), $\rho_{s}$ is the density of backfilling materials (= $\left.1,800 \mathrm{~kg} / \mathrm{m}^{3}\right), \rho_{w}$ is the density of water, $g$ is the gravitational acceleration, $d_{\mathrm{t}}$ is the thickness of the sand layer in front of the structure, $P_{\text {obmax }}$ is the maximum excess pore water pressure of the return flow, $\phi$ is the internal angle of the backfilling materials, $f$ is the coefficient of the suction force at the lowest edge of the structure $(\approx 1)$, and $V_{\max }$ is the maximum flow velocity of the return flow.

\subsection{CADMAS-SURF}

"CADMAS-SURF" [5] is a numerical model developed by Coastal Development Institute of Technology, Japan. This numerical model can simulate flow in a wave flume. This model based on 2D or 3D continuity equation (Eq. (9) for 2D) and 2D or 3D Navier Stroke's formulae (Eqs. (10) (17) for 2D). The free surface is handled by Volume of Fluid (VOF) technique [6]. This model can calculate the water pressure and the velocity on every designated point of the simulation.

The $3 \mathrm{D}$ version of this model could consider the effect of the properties of some specified materials (e.g., big stone and concrete block). However, in the case of fine materials such as sand and gravel, this model cannot consider an effect of these materials.

$$
\begin{aligned}
& \frac{\partial \gamma_{x} u}{\partial x}+\frac{\partial \gamma_{z} w}{\partial z}=0, \\
& \lambda_{v} \frac{\partial u}{\partial t}+\frac{\partial \lambda_{x} u u}{\partial x}+\frac{\partial \lambda_{z} w u}{\partial z} \\
& =-\frac{\gamma_{v}}{\rho} \frac{\partial p}{\partial x}+\frac{\partial}{\partial x}\left\{\gamma_{x} v_{e}\left(2 \frac{\partial u}{\partial x}\right)\right\} \\
& +\frac{\partial}{\partial z}\left\{\gamma_{z} v_{e}\left(\frac{\partial u}{\partial z}+\frac{\partial w}{\partial x}\right)\right\}-R_{x} \\
& \lambda_{v} \frac{\partial w}{\partial t}+\frac{\partial \lambda_{x} u w}{\partial x}+\frac{\partial \lambda_{z} w w}{\partial z} \\
& =-\frac{\gamma_{v}}{\rho} \frac{\partial p}{\partial z}+\frac{\partial}{\partial x}\left\{\gamma_{x} v_{e}\left(\frac{\partial w}{\partial x}+\frac{\partial u}{\partial z}\right)\right\} \\
& +\frac{\partial}{\partial z}\left\{\gamma_{z} v_{e}\left(2 \frac{\partial w}{\partial z}\right)\right\}-R_{z}-\gamma_{\nu} g \\
& \lambda_{v}=\gamma_{v}+\left(1-\gamma_{v}\right) C_{M}, \\
& \lambda_{x}=\gamma_{x}+\left(1-\gamma_{x}\right) C_{M}, \\
& \lambda_{z}=\gamma_{z}+\left(1-\gamma_{z}\right) C_{M} \text {, } \\
& R_{x}=\frac{1}{2} C_{D} \text { (1) } u \sqrt{u^{2}+w^{2}}, \\
& R_{z}=\frac{1}{2} C_{D} \text { (1) } w \sqrt{u^{2}+w^{2}} \text {, } \\
& \gamma_{v} \frac{\partial F}{\partial t}+\frac{\partial \gamma_{x} u F}{\partial x}+\frac{\partial \gamma_{z} w F}{\partial z}=0,
\end{aligned}
$$

where, $x$ and $z$ are the horizontal and vertical coordinates, $\gamma_{x}$ and $\gamma_{z}$ are the sectional transform ratio in horizontal and vertical direction, respectively, $\gamma_{v}$ is the porosity, $u$ and $w$ are the velocities in horizontal and vertical direction, respectively, $v_{e}$ is the kinematic viscosity, $p$ is the water pressure, $\rho$ is the water density, $\lambda_{v}, \lambda_{x}, \lambda_{z}$ are coefficients expressed in Eqs. (12) (14), $C_{M}$ is the coefficient of inertia, $R_{x}$ and $R_{z}$ are the drag force in the horizontal and vertical direction, respectively, $C_{D}$ is the drag force coefficient, $\Delta x, \Delta z$ are the mesh size in horizontal and vertical direction, respectively, and $F$ is the VOF function.

\section{Methodology}

\subsection{Wave flume experiment}

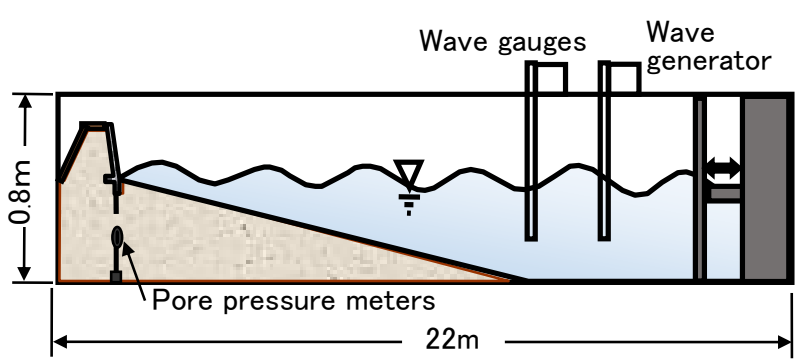

Fig.2 Wave flume experiment setup.

Some wave flume experiments were performed to get wave pressure distribution in a coastal dike and relation between suction rate and some concerned parameters. For these purposes, a dike model and a wave flume that has 
$0.5 \mathrm{~m}$ in width, $0.8 \mathrm{~m}$ in height, and $22.0 \mathrm{~m}$ in length and the ball-screw-driven wave generator were setup as shown in Fig.2. To get pore water pressures and pressure distribution in the dike, pore water pressure gauges were equipped at the inner length inside the dike of $0 \mathrm{~cm}, 5 \mathrm{~cm}$, $15 \mathrm{~cm}$, and $75 \mathrm{~cm}$. Moreover, to examine the effect of sand layer thickness affect the pore pressure, sand layer inside the dike was set to three cases: 1) before the suction, 2) in the middle of suction, and 3) at the end of suction.

The authors selected the case study of the Hirono coast, Shizuoka Prefecture, Japan as a prototype. This coast suffered suction damage due to Typhoon no. 9 in 1997. At that time, the significant wave height was $6.91 \mathrm{~m}$ and the significant wave period was $13.9 \mathrm{~s}$. So, in the experiments, the significant wave height and significant wave period were scaled to $0.23 \mathrm{~m}$ and $2.65 \mathrm{~s}$ by Froude law. Moreover, grain size was scaled from $0.4 \mathrm{~mm}$ to $0.2 \mathrm{~mm}$ by the similitude of beach profile given by Ito and Tsuchiya [7]. The results of the experiment are shown in Fig.3-5.

\subsection{Development of a new suction formula}

According to the Ioroi et al.'s formula (Eq. (1)) was designed for calculating suction rate by using maximum pore water pressure and maximum velocity of the single point at the lowest edge of the structure. So, to calculate suction rates on every point in the dike, the authors proposed a new suction formula, Eq. (18), which can use with calculated pressure and velocity from CADMASSURF.

$$
\frac{q}{w_{s} D_{50}}=\beta\left(\theta-\theta_{c}\right)
$$

And because of the empirical equation for calculating the proportional coefficient, Eq. (3), was derived for using with Eq. (1), the authors also proposed a new empirical equation for calculating the proportional coefficient, Eq. (18), which obtained by the relation between the suction rate and pore water pressure that can be measured in the experiments.

$$
\beta=0.142 e^{-0.25\left(\frac{D 50}{0.2 m m}\right)}
$$

\subsection{Modification coefficients to improve calculated pressures from CASMAS-SURF}

As CADMAS-SURF does not consider the effect of the sand layer inside the dike. So, the authors performed some experiments mentioned above and proposed three empirical equations for calculating modification coefficients to improve the calculated pressure from CADMAS-SURF.

\subsubsection{Modification coefficient for the inner length from the front of the dike, $C_{x}$.}

The result from the experiments shows that pore water pressures decrease when the inner length of the dike increases, as shown in Fig.3. According to this result, the empirical equation to calculate a modification coefficient for the inner length from the front of the dike, Eq. (20), could be obtained.

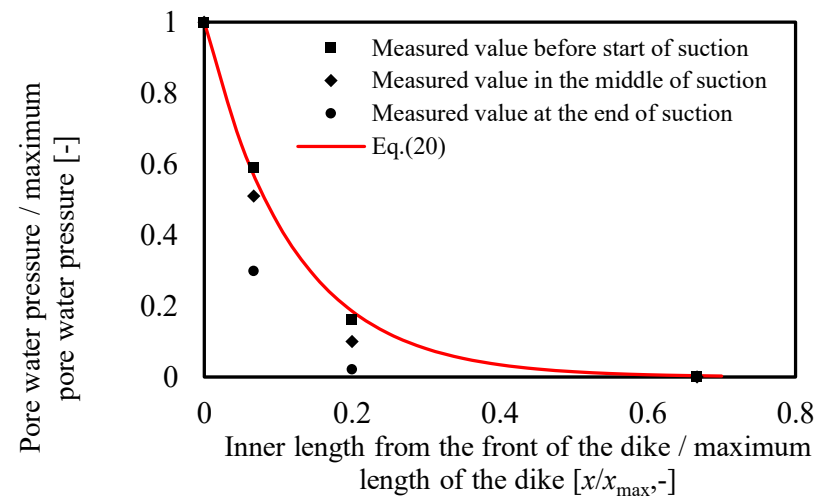

Fig. 3 Relation between pore pressure and inner length from the front of the dike.

$$
C_{x}=0.00022^{x / x_{\max }}
$$

\subsubsection{Modification coefficient for the sand layer thickness, $C_{d}$.}

From the above result, when we consider about the sand layer thickness affect pore water pressure, the result shows pore water pressures decrease when the sand layer thickness decrease. Fig. 4 shows the relation between modification coefficient and sand layer thickness. By this result, the authors obtained an empirical equation to calculate a modification coefficient for the sand layer thickness, Eq. (21).

$$
C_{d}=e^{0.269-\frac{0.263}{d / d_{\max }} e^{44.996-23.715 e^{\frac{-\left(x / x_{\max }\right)-3.265}{4.953}}} \ln \left(d / d_{\max }\right)}
$$

where, $d$ is the sand layer thickness, and $d_{\max }$ is the maximum sand layer thickness.

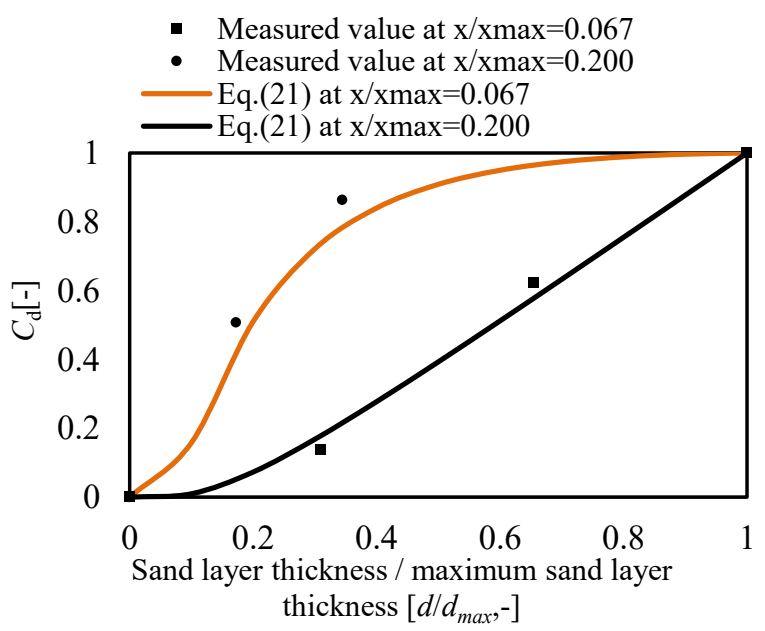

Fig. 4 Relation between $C_{\mathrm{d}}$ and sand layer thickness.

\subsubsection{Modification coefficient for grain size, $C_{D 50 \text {. }}$}


Yoshizawa et al. [4] presented the empirical equation to modify the calculated pressure from CADMAS-SURF, this equation can improve the effect of the median grain size into an account. However, by using this empirical equation to Eq. (19), the calculated result is overestimated. Therefore, the authors proposed a new empirical equation to calculate a modification coefficient for the grain size, Eq. (22).

$$
C_{D_{50}}=0.65\left(\frac{0.2}{D_{50}}\right)^{0.85}+0.35
$$

Finally, we can get the modified pressure by applying these three modification coefficients to the calculated pressure from CADMAS-SURF as expressed in Eq. (23). This modified pressure is used to calculate shear force instead of $P_{\text {obmax }}$ in Eq. (6).

$$
p=C_{x} C_{d} C_{D_{50}} p_{C A D}
$$

where, $p$ is the modified pressure, and $p_{\mathrm{CAD}}$ is the calculated pressure from CADMAS-SURF.

\section{The reliability of the method}

The reliability of the method was confirmed by a reproductive simulation of the experiment case. The calculated value from the simulation agreed with the measured value from the experiment as shown in Fig. 6.

Moreover, to confirm the applicability of the method, the suction phenomena on the Hirono coast was reproduced. Fig. 6 shows the simulation result on the Hirono coast. The simulated result agreed to the measured one, according to the field survey of Ioroi et al. that the accumulated suction rate was $28 \mathrm{~m}^{3} / \mathrm{m}$.

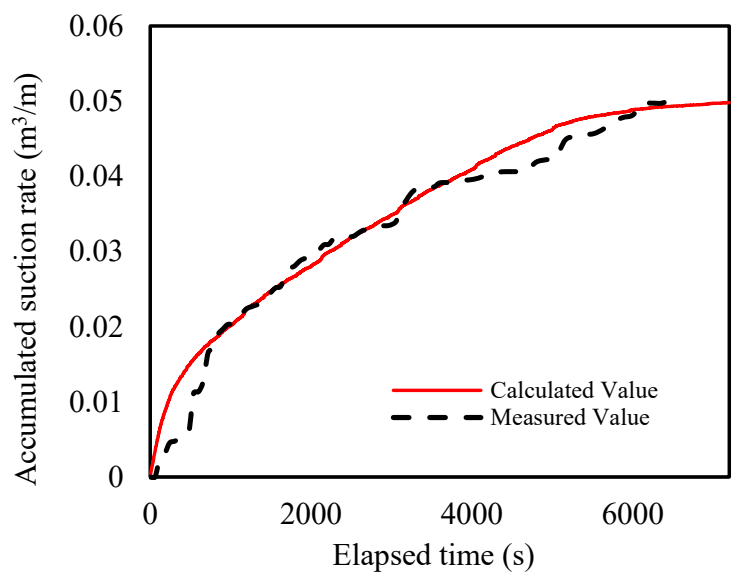

Fig. 5 Relation between accumulated suction rate and elapsed time.

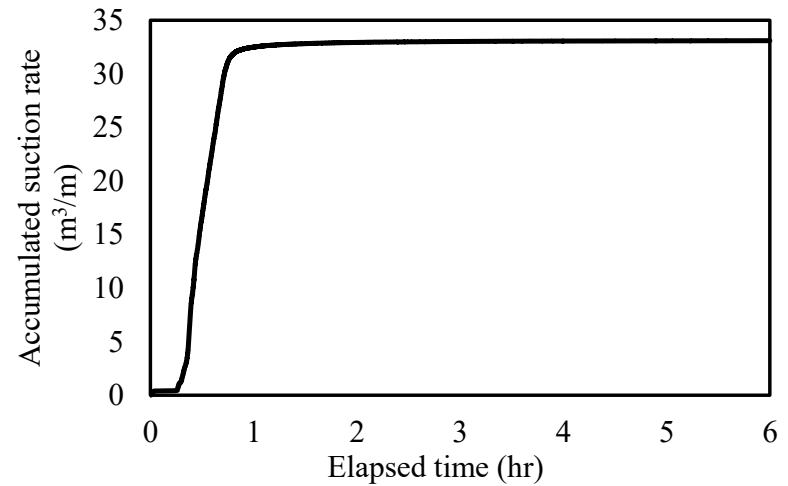

Fig. 6 Reproduction of suction phenomena in the Hirono coast.

\section{Conclusion}

The authors proposed Eqs.(18) (23) that can be used in CADMAS-SURF to calculate the suction rates to elapsed time. The reliability and the applicability of the method were confirmed by reproducing simulations of the experiment and the Hirono coast.

\section{References}

1. Yamamoto, Y, Minanmi, N (2009). "Experimental Investigation on Destruction Mechanism of Coastal Dyke Due to Big Waves," Journal of Japan Society of Civil Eng, B2-Vol.65, No.1, 901-905 (in Japanese).

2. Ioroi, M, Yamamoto, Y (2013). "Formula for Evaluating Suction Rate of Backfilling Materials from a Coastal Dike by Big Waves," Proc 23th Int Offshore and Polar Eng Conf, Alaska, USA, ISOPE, 1210-1216.

3. Ioroi, M, Yamamoto, Y (2015). "Improvement of a Suction Rate Formula from the Bottom of the Sheet Pile of a Coastal Dike," Proc 25th Int Offshore and Polar Eng Conf, Hawaii, USA, ISOPE, 3, 1483-1488.

4. Yoshizawa, S, Yamamoto, Y, and Kuisorn, W (2016). "Improvement of Methods for Calculating the Suction Rate from a Coastal Dike or a Seawall," Journal of Japan Society of Civil Eng, Vol. 72, No. 2, 1147-1152 (in Japanese).

5. Coastal Development Institute of Technology (2008). "CADMAS-SURF,"

http://www.cdit.or.jp/program/cadmasdownload.html (in Japanese).

6. Hirt, C, B. D. Nichols (1981). "Volume of Fluid (VOF) method for dynamics of boundaries," Journal of Computer Physics, 39, 201-225.

7. Ito, M, Tsuchiya, Y (1984). "Scale-Model Relationship of Beach Profile," Coastal Eng Proc, 19, 1386-1402. 